\title{
Cerebral palsy and obstetric-neonatological interventions
}

\author{
Jakub Mlodawski ${ }^{1,2}$, Marta Mlodawska ${ }^{3,4}$, Grazyna Pazera ${ }^{4}$, Wojciech Michalski ${ }^{5}$, \\ Tomasz Domanski ${ }^{2}$, Magdalena Dolecka-Slusarczyk ${ }^{6}$, \\ Stanislaw Gluszek ${ }^{3,7}$, Wojciech Rokita ${ }^{2,8}$

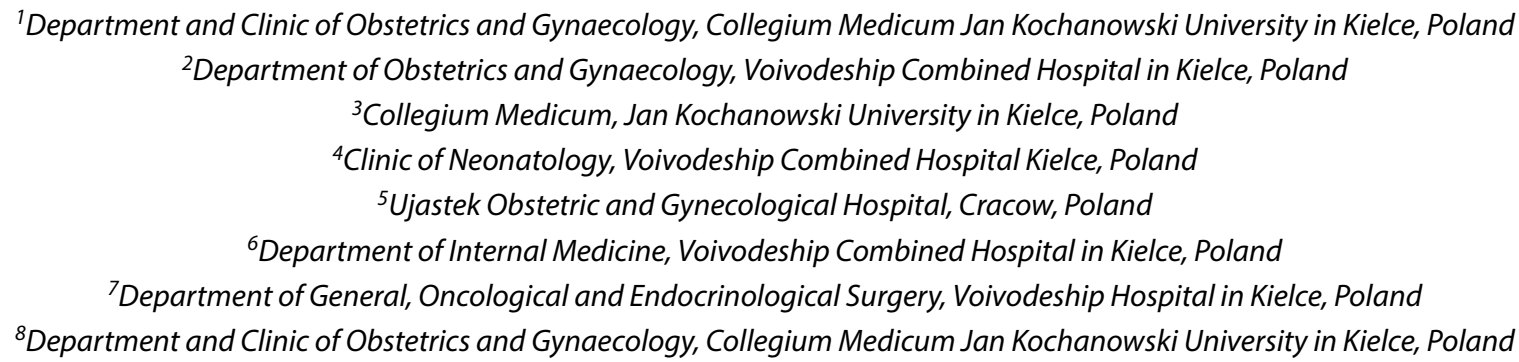

\begin{abstract}
Cerebral palsy is a disease that puts a great mental burden on caregivers and generates very high social costs. Children with $\mathrm{CP}$ require many years of rehabilitation and medical care. The etiology of the disease is undoubtedly multifactorial, and the pathogenesis is associated with focal damage to the central nervous system. One can find descriptions of well-documented interventions in the literature that reduce the risk of $\mathrm{CP}$ in certain groups of pregnant and neonatal patients, and interventions that have a potentially protective effect. In this review, we have analyzed the available literature in terms of prenatal and postnatal interventions that may have an impact on reducing the incidence of this condition in children.

Key words: cerebral palsy; magnesium sulfate; pogesterone; therapeutic hypothermia; Delayed Cord Clamping; antenatal corticosteroids
\end{abstract}

\section{CEREBRAL PALSY — DEFINITION}

Cerebral Palsy (CP) is a heterogeneous group of diseases whose common denominator is non-progressive damage to nerve tissue at an early stage of development. Symptoms of $\mathrm{CP}$ include irregularities in movement and posture. The range of possible damage is unusually large, and the very diagnosis of $\mathrm{CP}$ does not determine the degree of disability of a patient or the type of damage to the central nervous system. Children affected by CP include both independent patients and patients incapable of leading an independent existence. Co-existing problems may include intellectual, cognitive and sensory disorders as well as epilepsy and behavioral disorders. According to the definition, the damage is not progressive, but the general condition can change over the years due to treatment and the plasticity of the maturing nervous system.

\section{EPIDEMIOLOGY AND ETIOLOGY}

$\mathrm{CP}$ occurs in the population with a frequency of 1.3$-2.5 / 1000$ live births [1]. The biggest risk factors for CP are premature delivery and low birth weight. Among newborns with a mass between 1000 and $1499 \mathrm{~g}$, the incidence is $60.04 / 1000$ live births, and among newborns with a mass between 1500 and $2499 \mathrm{~g}$, the rate is $8.33 / 1000$ live births. Among newborns born before 28 weeks of pregnancy, the incidence of CP is estimated at 111/1000 live births, which decreases to about 1.35 among newborns born after 36 weeks of pregnancy (below the level for the general population). Despite these strong correlations between low gestational age and low birth weight, over half of children with cerebral palsy are born after week 36 of pregnancy [2]. In the case of premature babies, the risk of developing $\mathrm{CP}$ increases with complications resulting from 
premature birth such as periventricular leukomalacia, intraventricular bleeding and bronchopulmonary dysplasia [3]. The etiology of $\mathrm{CP}$ is undoubtedly multifactorial. In addition to premature delivery, the risk factors include intrauterine growth restriction (IUGR), intrauterine infections, antepartum hemorrhage, multiple pregnancy, placental pathology as well as congenital defects (mainly of the central nervous system) and genetic predisposition [3-5]. Although most of the causative factors occur in the prenatal and perinatal periods, about $10-18 \%$ of CP is the result of CNS damage during infancy and early childhood [5], i.e. during intensive brain development. They include sepsis, meningitis, kernicterus, head trauma, severe hypoxia and stroke (which is a consequence of, among other things, a congenital heart disease, vascular malformations or thrombotic disorders).

Despite significant progress in perinatal care, fetal monitoring during pregnancy and intranatally and an increase in the number of caesarean sections, no reduction in population incidence of CP was achieved [1]. There is a perception among the public (also in the medical community) that most $\mathrm{CP}$ cases are caused by hypoxic-ischemic injury during delivery. The American College of Obstetricians and Gynecologists and the American Academy of Pediatrics published objective criteria for intranatal asphyxia in 2003 (Tab. 1) [6].

Among Australian cohorts of neonates born in term, only $4 \%$ of patients met the criteria for intranatal asphyxia [7].

\section{SYMPTOMATOLOGY}

The extent of an expanding brain can be different, which translates into a large spectrum of different applications. Symptoms can only apply to precise movements or an independent existence. Despite the fact that access to the clinical presentation is limited and changes over time, it inhibits and changes the child's motor development. Diagnosis of CP is established over a period of time, never on a one-time basis. The first symptoms may be discreet, including emerging problems with gaining new skills by the child and problems with counteracting gravitational forces, e.g. lack of ability to stabilize the head and torso, sitting or walking in the expected period of life. Such symptoms, de-

\section{Table 1. Criteria for intranatal asphyxia (AAP, ACOG) [6]}

\section{Neonatal signs consistent with an acute peripartum or} intrapartum event:

1. Apgar score of $<5$ at 5 minutes and 10 minutes

2. Fetal umbilical artery acidemia: fetal umbilical artery $\mathrm{pH}<7.0$, or base deficit $\geq 12 \mathrm{mmol} / \mathrm{L}$, or both

3. Neuroimaging evidence of acute brain injury seen on brain MRI or MRS consistent with hypoxia-ischemia

4. Presence of multisystem organ failure consistent with hypoxicischemic encephalopathy

$\mathrm{MRI}$ - magnetic resonance imaging; MRS - magnetic resonance

spectroscopy; AAP - American Academy of Pediatrics; ACOG

- American College of Obstetricians and Gynecologists pending on the accuracy of the interview, suggest the first suspicion of the diseases. An experienced clinician is able to detect alarming symptoms, such as muscle exercises, fixed asymmetry, abnormal spontaneous motility, early. Therefore, children at risk (e.g. premature babies) must be referred to specialist care before other measures are taken. It is important to note that the problem may reveal itself after several different activities related to an apparently healthy full-term newborn, despite the absence of disturbing signs in the first days of life. The transformation of the brain is irreversible, however, due to the plasticity of the CNS, the damaged function may be taken over by other areas of the brain.

\section{PREVENTION - PROCEDURES TO REDUCE THE RISK OF CP}

Factors that damage the central nervous system can act at different stages of the development of the human brain, which is why potential preventive measures relate to different time frames.

Considering prematurity and low birth weight as the largest CP risk factors in the pediatric population, all interventions used in the prevention of preterm labor have potential protective effects. Randomized studies indicate the effectiveness of progesterone in the prevention of preterm births in specific patient groups. Patients with a history of preterm labor $[8,9]$ and patients with a short cervix in a single pregnancy benefit from prophylactic progesterone supplementation $[9,10]$, studies also indicate the effectiveness of progesterone in twin pregnancy with a short cervix in the second trimester, however, the strength of scientific evidence is lesser in this case [11, 12]. Shepherd et al. [13] found only one randomized work estimating the direct effect of the use of progesterone in $\mathrm{CP}$ reduction in their systematic review, 17-hydroxyprogesterone caproate was used intramuscularly in patients with single pregnancy and a history of premature labor, despite a reduction in the incidence of premature labor observed before 37 weeks of pregnancy [relative risk $(\mathrm{RR})=0.66,95 \%$ confidence interval $(\mathrm{Cl})=0.54-0.81]$, a reduction in neonatal intraventricular hemorrhage $(\mathrm{RR}=0.25,95 \% \mathrm{Cl}=0.08-0.82)$, the efficacy of progesterone during pregnancy in reducing $\mathrm{CP}$ incidence compared to mothers receiving placebo has not been confirmed (RR 0.14, 95\% Cl 0.01-3.48) [13]. It should be noted that the majority of conducted randomized trials to assess the effects of progesterone in the prevention of preterm labor were not designed to assess distant effects in children, so the research group in the said study is relatively small (a total of 274 children in the research group and placebo), which may result in insufficient statistical power to detect differences in the occurrence of complications with relatively low prevalence in the general population. 
Another intervention having proven effect in the prevention of premature labor is the use of cervical cerclage along with cervical shortening in the second trimester of pregnancy, which reduces the risk of labor before 37 and 34 weeks of pregnancy by an average of $23 \%(\mathrm{RR}=0.7795 \% \mathrm{Cl} 0.66-0.89)$ [14]. The meta-analysis did not show greater efficacy of the cervical cerclage, compared to placebo in reducing intraventricular hemorrhage, periventricular leukomalacia, respiratory distress syndrome (RDS) and necrotizing enterocolitis (NEC). We have not found studies assessing the long-term effects of this intervention on children in the literature, including assessing the development of cerebral palsy.

We cannot overlook the importance of using low doses of acetylsalicylic acid in the prevention of preeclampsia (PE) and intrauterine fetal growth disorder (IUGR) [15]. Preeclampsia is a dangerous complication for both the mother and the child. It is the cause of iatrogenic prematurity because the only effective treatment is childbirth. An ASPRE randomized study assessing the effectiveness of acetylsalicylic acid compared to placebo showed a $62 \%$ reduction in PE prevalence before 37 weeks of gestation [16]. The study also assessed the risk of fetal growth disorders, which are one of the main risk factors for $\mathrm{CP}$ as well, the risk of having a baby with a weight $<10$ percentile was $23 \%$ lower, and with a weight $<3$ percentile was $8 \%$ lower [16]. There are no studies in the literature directly assessing the effect of using low doses of acetylsalicylic acid in the prevention of PE on the incidence of $C P$, however, it seems that $P E$ screening and the use of ASA in high-risk patients may have a beneficial effect in the prevention of $C P$ in the population. This issue, however, requires further prospective research.

\section{Antenatal steroid therapy}

Antenatal steroid therapy has been used for almost 50 years in obstetrics. A published meta-analysis of 30 randomized studies confirmed the efficacy of antenatal steroid therapy in preventing RDS in newborns ( $R R=0.66,95 \%$ $\mathrm{Cl}$ 0.56-0.77), preventing perinatal death of newborns $(\mathrm{RR}=0.72 \mathrm{Cl} 95 \% 0.58-0.89)$, intraventricular bleeding $(\mathrm{RR}=0.54 \mathrm{Cl} 95 \% 0.43-0.69)$, NEC (RR $=0.50,95 \% \mathrm{Cl} 0.32-$ -0.78 ) and the development of sepsis in the first two days of life (RR $0.60,95 \% \mathrm{Cl} 0.41-0.88$ ) [17]. Studies of the Polish population have also shown a reduction in the risk of RDS, bronchopulmonary dysplasia and mortality of neonates born $\leq 32$ weeks of pregnancy [18]. The abovementioned beneficial effects for newborns beg the question about the long-term effect on the occurrence of $\mathrm{CP}$ in the population of premature babies. In the cited meta-analysis, Roberts et al. [17] take into account five randomized studies assessing the occurrence of this complication. There was no significant difference between groups in the occurrence of $C P(R R=0.60 \mathrm{Cl}$ $95 \% 0.34-1.03, p=0.06$ ), however, it should be noted that the achieved relative risk value is close to statistical significance. Given the proven effects of antenatal steroid therapy, it is currently not possible to perform placebo-controlled or randomized controlled trials for ethical reasons. Another meta-analysis, that also included observational studies, indicates the clinical benefits of a single course of antenatal steroid therapy in reducing the risk of $C P$ diagnosed in the first year of life or later, the percentage of CP diagnoses was $32 \%$ lower in patients whose mothers received a course of steroid therapy during pregnancy terminated prematurely $(\mathrm{RR}=0.68,95 \% \mathrm{Cl} 0.56-0.82)$. Steroid therapy also reduced the risk of severe disability ( $R R=0.79,95 \% \mathrm{Cl} 0.73-0.85)$ [19].

\section{THE USE OF MAGNESIUM SULFATE $\left(\mathrm{MGSO}_{4}\right)$}

A meta-analysis including five randomized studies evaluating the effectiveness of magnesium sulfate in the prevention of CP in the population of premature babies is available in the literature. The upper gestational age limit at the stage of randomization was between 30 and 34 weeks of pregnancy [20]. The meta-analysis showed a $30 \%$ reduction in the incidence of $\mathrm{CP}$ in the case of children born before 32-34 weeks of gestation ( $R R=0.70, \mathrm{Cl} 95 \%=0.55-0.89)$ and moderate or severe CP by $40 \%(R R=0.60, C I$ 95\% $=0.43-$ -0.84). The composite end point of cerebral palsy or death did not reduce significantly in the entire study population ( $R R=$ 0.92, 95\% Cl 0.83-1.03), however, a reduction was observed in the subgroup of randomized patients in studies assessing only neuroprotective effects (RR $0.85,95 \% \mathrm{Cl} 0.74-0.98$ ). The meta-analysis did not report that in utero exposure to magnesium sulfate increased the risk of neonatal death. The number of patients to treat in order to prevent one case of cerebral palsy was 46 in the pregnancy group $<30$ weeks of pregnancy, and 56 in the pregnancy group of gestational ages between 32 and 34 weeks since the last menstrual period (95\% Cl 26-187). Magnesium sulfate administration protocols differed between the studies, however, an intervention always began with a dose of $4-6 \mathrm{~g}$ in the first 20-30 $\mathrm{min}$, then the infusion was continued at $2 \mathrm{~g} / \mathrm{h}$ for $12 \mathrm{~h}$ or $1 \mathrm{~g} / \mathrm{h}$ for $24 \mathrm{~h}$. The neuroprotective mechanism of magnesium sulfate is unknown. At least four potential therapeutic models are postulated: prevention of glutamate excitotoxicity on the postsynaptic membrane by blocking NDMA receptors, antioxidant and anti-inflammatory properties as well as fetal cerebral circulation properties [21]. Only one of the randomized studies included the long-term effects of magnesium sulfate treatment. In a multicenter ACTO$\mathrm{MgSO}_{4}$ study in which patients giving birth $<30$ weeks gestation were randomized $(n=1062)$, the born children were included in an early-school-age medical examination [22]. The mean corrected age at the time of the study time was 8.4 years old in both the study group and the placebo group. The occurrence of cerebral palsy did not differ significantly 
between the groups [odds ratio $(\mathrm{OR})=1.26,95 \% \mathrm{Cl} 0.84-$ $1.91, \mathrm{p}=0.27]$, nor did the mortality of patients in both groups ( $R R=0.8095 \% \mathrm{Cl} 0.62-1.03, \mathrm{p}=0.08$ ). The observed relative risk of mortality had a $\mathrm{p}$-level close to 0.05 , which implies the need for further studies due to the possibility of type Il error associated with insufficient statistical power (the power of comparison in the study was $80 \%$ ).

Currently, the World Health Organization recommends the administration of magnesium sulfate to patients who are at a high risk of preterm labor in both single and multiple pregnancies within the next 24 hours, and whose gestational age is less than 34 weeks of pregnancy [23]. It is recommended to administer 4-6 $\mathrm{g}$ in a bolus within 20-30 minutes followed by an infusion for $24 \mathrm{~h}-1-2 \mathrm{~g} / \mathrm{h}$. The infusion should be continued until delivery, and if no delivery occurs one day after the treatment had started, the infusion should be terminated. The American College of Obstetricians and Gynecologists in its opinion from 2010 (which was upheld in 2018) and the Royal Society of Gynecologists and Obstetricians, in a scientific opinion from 2011, recommend the administration of magnesium sulfate in threatening preterm labor. Despite evidence of its effectiveness in the literature, there is a need for further studies to assess optimal dosage, gestational age and obstetric results in the absence of preterm labor as well as long-term effects.

\section{DELAYED CORD CLAMPING}

Early cord clamping is defined as tightening of the umbilical cord within 60 seconds after birth, while late umbilical cord clamping takes place after 1 minute of life (optimally 2-3 minutes) or after the ripening of the umbilical cord. After birth, thanks to the continuous exchange of blood in the pulsating umbilical cord between the placenta of the mother and the newborn, the so-called placental transfusion, mostly in the first 3 minutes after birth. The time gained until the umbilical cord is tightened allows the newborn to change physiologically and transit from fetal to ectopic life. Late cord clamping, recommended by numerous scientific societies and WHO [24], has a beneficial effect on the child's health and nutrition. It is also safe for mother. There is no increase risk for maternal adverse outcome like postpartum hemorrhage, lower postpartum hemoglobin levels or the need for blood transfusion. It is recommended for both full-term and premature babies. In the absence of spontaneous breathing in the first seconds after birth, stimulation (drainage, tactile stimulation) should be performed before the umbilical cord is tightened and respiratory resuscitation begins. Early umbilical cord clamping is necessary only in strictly justified cases of unstable condition of the child or mother: (a newborn requiring immediate respiratory resuscitation, unexpected interruption of maternal-fetal circulation (detachment of the umbilical cord, separation of the placenta), inhibition of intrauterine growth with abnormal flow in the umbilical cord because of intrauterine hypoxia resulting in polycythemia and increased blood viscosity) $[24,25]$. It appears that late umbilical cord clamping supports and stabilizes the transformation of fetal circulation into ectopic circulation in premature babies and thereby reduces the risk of intraventricular bleeding and necrotizing enterocolitis - as indicated by some studies and emphasized by WHO in its official recommendations [24, 26]. Immediate dismissal may result in, among others, hypotension provoking the occurrence of intraventricular bleeding in the immature brain of premature neonates. The latest systematic review evaluating the effects of late vs early omphalectomy in 2834 premature newborns from 2018 indicates a $30 \%$ reduction in hospital mortality (RR $0.68 ; 95 \% \mathrm{Cl} 0.52-0.90$; number needed to benefit $33,95 \% \mathrm{Cl}$ $20-100)$; an increase in hematocrit by an average of $2.73 \%$ $(95 \% \mathrm{Cl} 1.94-3.52)$, a decrease in the risk of blood transfusion by $10 \%(95 \% \mathrm{Cl} 6-13 \%)$, a higher bilirubin concentration by an average of 4 micromoles/L withoutincreasing mortality [27]. However, there were no differences in both groups in the frequency of severe intraventricular bleeding, brain damage, necrotizing enteritis or late-onset sepsis (chronic lung disease, mechanical ventilation) and others. These data contradict the results described in the previous meta-analysis from 2012, where it was demonstrated that late umbilical cord clamping statistically reduced the risk of these complications in premature babies in a significant manner [28]:

- lower risk of first and second degree intraventricular bleeding (RR 0.59, 95\% Cl 0.41-0.85);

- lower risk of necrotizing enterocolitis (RR $0.62 ; 95 \% \mathrm{Cl}$ 0.43-0.9);

- lower risk of anemia requiring transfusion (RR 0.61; 95\% Cl 0.46-0.81);

- no difference in the prevention of severe intraventricular bleeding (III, IV degree) - however, the authors point to the methodological limitations of the study.

The presented data are inconclusive, but none of the studies showed a negative impact of delayed cord clamping on children born prematurely, while showing the benefits that newborns enjoy. The impact on the risk of complications due to premature birth, including intraventricular hemorrhage, requires further analysis.

In the case of term newborns, children benefits from delayed cord clamping, first of all, there is a reduced risk of iron deficiency in the first months of life, which has a significant impact on neurological development. Due to the high growth rate, children are very sensitive to iron deficiency, which may result in psychomotor retardation in the future, and as indicated by epidemiological and experimental studies, such abnormalities appearing at an early stage of development may be irreversible despite the subsequent correction of iron deficiency [29]. 
Extensive meta-analysis [30] from 2013 including 3911 mothers and their newborn babies born on time, assessing early vs late umbilical cord clamping showed: lower hemoglobin concentration in the first 24-48 h of life in early group neonates [mean difference (MD) $-1.49 \mathrm{~g} / \mathrm{dL}, 95 \%$ $\mathrm{Cl} 1.78-1.21 ; \mathrm{n}=884]$, not observed in the following days of life; over twice as high risk of iron deficiency in 3-6 months (14\% vs $8 \%$, RR $2.65,95 \% \mathrm{Cl} 1.04-6.73, \mathrm{n}=1152)$ and $40 \%$ lower risk of phototherapy due to jaundice ( $2.74 \%$ vs $4.36 \%$ ).

One randomized study, which looked at 263 children born from low-risk pregnancies, showed a beneficial effect of late vs early umbilical cord clamping on neurological development at the age of 4, especially in boys [31].

Umbilical cord milking, i.e. pumping blood from the umbilical cord towards the child, should not be confused with the late cord clamping process. The optimal time for milking or its duration is currently unknown. It is also unknown whether milking can be an alternative to late umbilical cord clamping, especially in premature babies (studies in progress). One study has shown that an alternative to delayed cord clamping $>30$ seconds can be 4 times milking the available cord length at a speed of $20 \mathrm{~cm} / 2$ seconds [32].

\section{THERAPEUTIC HYPOTHERMIA}

Neonates born after the $35^{\text {th }}$ week of gestation who experience a perinatal episode of hypoxia that may result in perinatal hypoxic-ischemic encephalopathy, which may lead to $C P$, benefit from therapeutic hypothermia. The use of therapeutic hypothermia leads to an improvement in the survival rate with normal neurological development at the age of 18 months ( $40 \%$ vs $24 \%$, RR $1.63,95 \%$ Cl $1.36-1.95$ ) and a reduction in the risk of death and major neurological disorders at the age of 18 months (48\% vs $63 \%$, RR 0.76 , $95 \% \mathrm{Cl} 0.69-0.84$ ) [33].

Therapeutic hypothermia must be implemented in the first 6 hours of life. This is the approximate latency time between the primary phase (necrosis) and the secondary phase (apoptosis) of biochemical neuronal damage, although it has been proven that the more severe the hypoxic-ischemic injury, the shorter the latency period [34].

Indications for hypothermia [35]:

- $\mathrm{pH} \leq 7.0$ (special attention should also be paid to $\mathrm{pH}$ in the range of 7.01-7.15) and/or BE base deficiency of at least $16 \mathrm{mmol} / \mathrm{l}$ in a cord blood sample or a blood sample taken within 1 hour of life;

- 1 of the following:

- Apgar score $\leq 5$ in 1, 3, 5, 10 minute after birth;

- continuous resuscitation within 10 minutes after birth;

- neurological symptoms indicative of moderate/severe encephalopathy on clinical excamination (the Sarnat scale is used for qualification).

\section{NEONATAL CARE}

Intensive and individualized neonatological care in children particularly vulnerable to CNS damage (newborns with very low birth weight, newborns suspected of hypoxic-ischemic encephalopathy) aims to reduce the likelihood of long-term neurological sequelae. Over the past 20 years, we have seen unprecedented advances in intensive neonatal care. Technological development and increasing experience have helped to save smaller children and increased effective prevention and treatment of typical complications in the case of premature neonates.

\section{SUMMARY}

The interventions outlined above have proven or potentially protective effects on the risk of CP in children. Even though there are no direct studies to assess the reduction of $\mathrm{CP}$ incidence in the intervention group, we have no doubt that the interventions should be part of good medical practice in every perinatal and postnatal care ward.

\section{REFERENCES}

1. Winter S, Autry A, Boyle C, et al. Trends in the prevalence of cerebral palsy in a population-based study. Pediatrics. 2002; 110(6): 1220-1225, doi: 10.1542/peds.110.6.1220, indexed in Pubmed: 12456922.

2. Hjern A, Thorngren-Jerneck K. Perinatal complications and socio-economic differences in cerebral palsy in Sweden - a national cohort study. BMC Pediatr. 2008; 8: 49, doi: 10.1186/1471-2431-8-49, indexed in Pubmed: 18973666.

3. Kornacka MK, Bokiniec R, Bargiel A. [Risk factors for preterm encephalopathy]. Ginekol Pol. 2009; 80(8):620-623, indexed in Pubmed: 19824462.

4. Strijbis EMM, Oudman I, van Essen P, et al. Cerebral palsy and the application of the international criteria for acute intrapartum hypoxia. Obstet Gynecol. 2006; 107(6): 1357-1365, doi: 10.1097/01. AOG.0000220544.21316.80, indexed in Pubmed: 16738164.

5. Pharoah PO, Cooke T, Rosenbloom L. Acquired cerebral palsy. Arch Dis Child. 1989; 64(7): 1013-1016, doi: 10.1136/adc.64.7.1013, indexed in Pubmed: 2629622.

6. Hankins G. Defining the pathogenesis and pathophysiology of neonatal encephalopathy and cerebral palsy. Obstetrics \& Gynecology. 2003; 102(3): 628-636, doi: 10.1016/s0029-7844(03)00574-x.

7. Strijbis EMM, Oudman I, van Essen $P$, et al. Cerebral palsy and the application of the international criteria for acute intrapartum hypoxia. Obstet Gynecol. 2006; 107(6): 1357-1365, doi: 10.1097/01. AOG.0000220544.21316.80, indexed in Pubmed: 16738164.

8. Dodd JM, Jones L, Flenady $\mathrm{V}$, et al. Prenatal administration of progesterone for preventing preterm birth in women considered to be at risk of preterm birth. Cochrane Database Syst Rev. 2013(7): CD004947, doi: 10.1002/14651858.CD004947.pub3, indexed in Pubmed: 23903965.

9. Bomba-Opoń D, Czajkowski K, Karowicz-Bilińska A, et al. Polish Gynecological Society. [Recommendations of the Polish Gynecological Society concerning application of progesterone in obstetrics and gynecology]. Ginekol Pol. 2015; 86(3): 234-238, indexed in Pubmed: 25920316.

10. Romero $\mathrm{R}$, Nicolaides $\mathrm{KH}$, Conde-Agudelo $\mathrm{A}$, et al. Vaginal progesterone decreases preterm birth $\leq 34$ weeks of gestation in women with a singleton pregnancy and a short cervix: an updated meta-analysis including data from the OPPTIMUM study. Ultrasound Obstet Gynecol. 2016; 48(3): 308-317, doi: 10.1002/uog.15953, indexed in Pubmed: 27444208.

11. Romero R, Conde-Agudelo A, El-Refaie W, et al. Vaginal progesterone decreases preterm birth and neonatal morbidity and mortality in women with a twin gestation and a short cervix: an updated meta-analysis of individual patient data. Ultrasound Obstet Gynecol. 2017; 49(3): 303-314, doi: 10.1002/uog.17397, indexed in Pubmed: 28067007.

12. Huras $\mathrm{H}$, Kalinka J, Dębski R. Short cervix in twin pregnancies: current state of knowledge and the proposed scheme of treatment. Ginekol Pol. 2017; 88(11): 626-632, doi: 10.5603/GP.a2017.0112, indexed in Pubmed: 29303217. 
13. Shepherd E, Salam RA, Middleton P, et al. Antenatal and intrapartum interventions for preventing cerebral palsy: an overview of Cochrane systematic reviews. Cochrane Database Syst Rev. 2017; 8: CD012077, doi: 10.1002/14651858.CD012077.pub2, indexed in Pubmed: 28786098.

14. Alfirevic Z, Stampalija T, Medley N. Cervical stitch (cerclage) for preventing preterm birth in singleton pregnancy. Cochrane Database Syst Rev. 2017; 6: CD008991, doi: 10.1002/14651858.CD008991.pub3, indexed in Pubmed: 28586127.

15. Kosinski P, Sarzynska-Nowacka U, Fiolna M, et al. The practical use of acetylsalicylic acid in the era of the ASPRE trial. Update and literature review. Ginekol Pol. 2018; 89(2): 107-111, doi: 10.5603/GP.a2018.0018, indexed in Pubmed: 29512816.

16. Rolnik DL, Wright $D$, Poon LC, et al. Aspirin versus Placebo in Pregnancies at High Risk for Preterm Preeclampsia. N Engl J Med. 2017; 377(7): 613-622, doi: 10.1056/NEJMoa1704559, indexed in Pubmed: 28657417.

17. Roberts D, Brown J, Medley N et al. Antenatal corticosteroids for accelerating fetal lung maturation for women at risk of preterm birth. Cochrane Database Syst Rev. 2017; 3: CD004454, doi: 10.1002/14651858. CD004454.pub3, indexed in Pubmed: 28321847.

18. Borszewska-Kornacka MK, Gulczyńska E, Kostuch M, et al. Antenatal corticosteroids and respiratory distress syndrome - the first Polish national survey. Ginekol Pol. 2016; 87(7): 498-503, doi: 10.5603/GP.2016.0033, indexed in Pubmed: 27504942

19. Sotiriadis A, Tsiami A, Papatheodorou S, et al. Neurodevelopmental Outcome After a Single Course of Antenatal Steroids in Children Born Preterm: A Systematic Review and Meta-analysis. Obstet Gynecol. 2015; 125(6): 1385-1396, doi: 10.1097/AOG.0000000000000748, indexed in Pubmed: 26000510

20. Costantine MM, Weiner SJ. Eunice Kennedy Shriver National Institute of Child Health and Human Development Maternal-Fetal Medicine Units Network. Effects of antenatal exposure to magnesium sulfate on neuroprotection and mortality in preterm infants: a meta-analysis. Obstet Gynecol. 2009; 114(2 Pt 1):354-364, doi: 10.1097/AOG.0b013e3181ae98c2, indexed in Pubmed: 19622997.

21. Costantine MM, Drever N. Antenatal exposure to magnesium sulfate and neuroprotection in preterm infants. Obstet Gynecol Clin North Am. 2011; 38(2): 351-366, xi, doi: 10.1016/j.ogc.2011.02.019, indexed in Pubmed: 21575805.

22. Doyle LW, Anderson PJ, Haslam R, et al. Australasian Collaborative Trial of Magnesium Sulphate (ACTOMgSO4) Study Group. School-age outcomes of very preterm infants after antenatal treatment with magnesium sulfate vs placebo. JAMA. 2014; 312(11): 1105-1113, doi: 10.1001/jama.2014.11189, indexed in Pubmed: 25226476.

23. WHO recommendation on the use of magnesium sulfate for foetal protection from neurological complications; 17 November 2015, The WHO Reproductive Health Library.
24. World Health Organization. Guideline: delayed umbilical cord clamping for improved maternal and infant health and nutrition outcomes. 2014.

25. Guidelines on basic newborn resuscitation. Geneva: World Health Organization; 2012. http://apps.who.int/iris/bitstre am/10665/75157/1/9789241503693_eng.pdf?ua=1 (16.06.2014).

26. Mercer JS, Vohr BR, McGrath MM, et al. Delayed cord clamping in very preterm infants reduces the incidence of intraventricular hemorrhage and late-onset sepsis: a randomized, controlled trial. Pediatrics. 2006; 117(4): 1235-1242, doi: 10.1542/peds.2005-1706, indexed in Pubmed: 16585320.

27. Fogarty M, Osborn DA, Askie $L$, et al. Delayed vs early umbilical cord clamping for preterm infants: a systematic review and meta-analysis. Am J Obstet Gynecol. 2018; 218(1): 1-18, doi: 10.1016/j.ajog.2017.10.231, indexed in Pubmed: 29097178.

28. Rabe H, Diaz-Rossello JL, Duley L, et al. Effect of timing of umbilical cord clamping and other strategies to influence placental transfusion at preterm birth on maternal and infant outcomes. Cochrane Database Syst Rev. 2012(8): CD003248, doi: 10.1002/14651858.CD003248.pub3, indexed in Pubmed: 22895933.

29. Guideline: Intermittent iron supplementation in preschool and school-age children. Geneva: World Health Organization; 2011. https:// apps.who.int/iris/bitstream/handle/10665/148793/9789241508209_eng. pdf;isessionid=02EE631FFDF307955726827FCCB2B8AE? sequence $=1$.

30. McDonald SJ, Middleton P, Dowswell T, et al. Effect of timing of umbilical cord clamping of term infants on maternal and neonatal outcomes. Cochrane Database Syst Rev. 2008; 9(2): CD004074-397, doi: 10.1002/14651858.CD004074.pub2, indexed in Pubmed: 18425897.???

31. Andersson $\mathrm{O}$, Lindquist $\mathrm{B}$, Lindgren $\mathrm{M}$, et al. Effect of Delayed Cord Clamping on Neurodevelopment at 4 Years of Age: A Randomized Clinical Trial. JAMA Pediatr. 2015; 169(7): 631-638, doi: 10.1001/jamapediatrics.2015.0358, indexed in Pubmed: 26010418.

32. Rabe H, Jewison A, Alvarez RF, et al. Brighton Perinatal Study Group. Milk ing compared with delayed cord clamping to increase placental transfusion in preterm neonates: a randomized controlled trial. Obstet Gynecol. 2011; 117(2 Pt 1): 205-211, doi: 10.1097/AOG.0b013e3181fe46ff, indexed in Pubmed: 21252731.

33. Tagin MA, Woolcott CG, Vincer MJ, et al. Hypothermia for neonata hypoxic ischemic encephalopathy: an updated systematic review and meta-analysis. Arch Pediatr Adolesc Med. 2012; 166(6): 558-566, doi: 10.1001/archpediatrics.2011.1772, indexed in Pubmed: 22312166.

34. Gadzinowski J, Gulczyńska E, Michniewicz B, et al. [Therapeutic hypothermia for neonatal hypoxic-ischemic encephalopathy]. Ginekol Pol. 2012; 83(3): 214-218, indexed in Pubmed: 22568198.

35. Papile LA, Baley JE, Benitz W, et al. Committee on Fetus and Newborn. Hypothermia and neonatal encephalopathy. Pediatrics. 2014; 133(6): 1146-1150, doi: 10.1542/peds.2014-0899, indexed in Pubmed: 24864176. 